\title{
PVA and PCL Nanofibers Are Suitable for Tissue Covering and Regeneration
}

\author{
J. BEZNOSKA ${ }^{1}$, J. UHLÍK ${ }^{2}$, A. KESTLEROVÁ ${ }^{3,4}$, M. KRÁLOVIČ ${ }^{4,5,6}$, R. DIVÍN ${ }^{4,5,6}$,

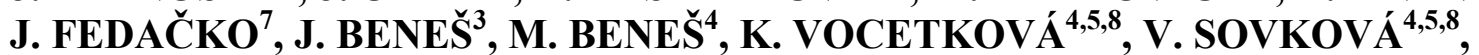 \\ A. NEČAS ${ }^{9}$, A. NEČASOVÁ ${ }^{9}$, J. HOLEŠOVSKÝ ${ }^{1}$, E. AMLER $^{4,5,6}$
}

${ }^{1}$ Rudolph and Stephanie Hospital, Benešov, Czech Republic, Second Faculty of Medicine, Charles University, Prague, Czech Republic, ${ }^{2}$ Department of Histology and Embryology, Second Faculty of Medicine, Charles University, Prague, Czech Republic, ${ }^{3}$ Institute of Biophysics and Informatics, First Faculty of Medicine, Charles University, Prague, Czech Republic, ${ }^{4}$ Department of Biophysics, Second Faculty of Medicine, Charles University, Prague, Czech Republic, ${ }^{5}$ Czech Technical University in Prague, University Centre for Energy Efficient Buildings, Buštěhrad, Czech Republic, ${ }^{6}$ Czech Technical University in Prague, Faculty of Biomedical Engineering, Kladno, Czech Republic, ${ }^{7}$ Department of Medical and Clinical Biophysics, Faculty of Medicine, Pavol Jozef Šafárik University, Košice, Slovakia, ${ }^{8}$ Institute of Experimental Medicine of the Czech Academy of Sciences, Prague, Czech Republic, ${ }^{9}$ Faculty of Veterinary Medicine, University of Veterinary and Pharmaceutical Sciences Brno, Brno, Czech Republic

Received October 4, 2019

Accepted December 2, 2019

\section{Summary}

The aim of the study was to evaluate the safety and efficacy of a new therapeutic approach to skin defects resulting from split thickness grafting. Within the study, nanofiber-based dressings fabricated using polyvinyl alcohol (PVA) and poly- $\varepsilon$-caprolactone $(\mathrm{PCL})$ were used, with different mass density. The study was performed in 1 female minipig. Nine defects (approx. $4 \times 4 \mathrm{~cm}$ ) were made in the superficial skin layer. The tested materials were applied to the squared skin defect and covered by a Jelonet paraffin gauze, sutured in the corners of the defects. The animal was monitored daily during the healing process ( 21 days). On day 5,12 , and 27 , the healing of the wound was evaluated, and a biopsy was performed for further histologic testing. At the end of the study (on day 27 after the procedure), the animal was euthanized, and a standard pathologic evaluation was performed. We can conclude that the nanofiber scaffold which was well tolerated, could be used as a smart skin cover which could be functionalized with another bioactive substances directly on the surgeon table, among potential bioactive substances belong platelet derivatives, antibiotics, etc.

\section{Key words}

Wound healing • Chronic wounds • Nanogauze • Nanofiber • Polyvinyl alcohol • Polycaprolactone

\section{Corresponding author}

Jiří Beznoska, Nemocnice Rudolfa a Stefanie Benešov, a. S., Máchova 400, Benešov 256 01, Czech Republic. E-mail: jiri.beznoska@hospital-bn.cz

\section{Introduction}

Wound healing is a complex biological process mediated by the interaction of signal molecules and mesenchymal cells (Crovetti et al. 2004). When the integrity of the epidermal barrier is disrupted, a blood clotting cascade is activated and platelets release numerous growth factors (GFs), such as epidermal growth factor (EGF), platelet-derived growth factor (PDGF) and transforming growth factor $\beta$ (TGF- $\beta$ ) (Barrientos et al. 2008). The released GFs attract immune cells to remove contaminating bacteria and damaged tissue and stimulate fibroblasts' proliferation and synthesis of new extracellular matrix (ECM) (Werner et al. 2003). Within hours after the injury, re-epithelialization starts via the EGF stimulation of keratinocyte migration and proliferation. Once the wound is closed, keratinocytes undergo stratification and differentiation in order to restore the epidermal barrier. 
Disruption of the fine balance may result in a poorly healing wound.

Faulty wound healing is becoming a global healthcare problem (Rieger et al. 2013). According to Mustoe (2004) the majority of chronic wounds can be classified into 3 categories - venous, diabetic and pressure ulcers. In the United States $1 \%$ of the population and up to $3.5 \%$ of people over 65 years of age suffer from venous ulcers (Hess 2005). The International Diabetic Federation in its 2014 report stated there are 387 million people living with diabetes worldwide, approximately $15 \%$ of them develop at least one diabetic ulcer. Effective wound dressings are thus needed (Rieger et al. 2013).

Wound dressings protect the wound and facilitate different aspects of healing (Rieger et al. 2013). Generally, they should provide a suitable microenvironment at the wound/dressing interface. They should absorb excess exudate, provide mechanical and bacterial protection and allow exchange of gases and fluids (Zahedi et al. 2010). These requirements could be met by electrospun nanofibrous mats. Electrospinning is a unique technique that uses a strong electric field to generate polymeric nanofibers. Such fibers are of a nanoscale diameter and thus mimic the microarchitecture of the extracellular matrix. They exhibit high porosity, with the interconnected pores facilitating the exchange of nutrients and gases, moisturization of the wound and drainage of the excess fluid. Moreover, their high surface to volume ratio favors the adsorption of bioactive compounds (Chakraborty et al. 2009). By incorporating bioactive compounds (e.g. growth factors) into the scaffold, one can mimic the function of ECM as well (Chew et al. 2006).

Chronic wounds generally exhibit a decrease in the availability of growth factors (GFs) (Crovetti et al. 2004). GFs delivered exogenously are usually not very effective, since they tend to diffuse away from the wound and are enzymatically deactivated. Conventional ways of delivery (e.g. bolus administration) are thus less likely to obtain promising results. Currently, new strategies are being employed to deliver high concentrations of multiple endogenous GFs to the site of interest (Chen et al. 2010).

The aim of this study was to test a wound dressing based on two types of nanofibers from polyvinyl alcohol (PVA) and poly- $\varepsilon$-caprolactone (PCL) on a model of a large animal and to investigate any potential adverse effects of a new therapeutic approach to superficial skin defects, as well as efficacy. Minipigs were chosen as a relevant laboratory animal model for assessment of novel techniques in skin defect therapy.

\section{Methods}

\section{Nanofiber preparation}

Nanogauze (size $6 \times 6 \mathrm{~cm}$ ) has been prepared as a composite material from a classical gauze with a nanofiber layer from PVA (with mass density $2 \mathrm{~g} / \mathrm{m}^{2}$, $3,5 \mathrm{~g} / \mathrm{m}^{2}$ and $5 \mathrm{~g} / \mathrm{m}^{2}$ ), and PCL (with mass density $4 \mathrm{~g} / \mathrm{m}^{2}$, $6.5 \mathrm{~g} / \mathrm{m}^{2}, 13 \mathrm{~g} / \mathrm{m}^{2}$ and $15 \mathrm{~g} / \mathrm{m}^{2}$ ), respectively,

\section{Experimental animal and treatment}

Minipig (Sus scrofa f. domestica) has been used as a large animal model.

The procedure was performed under general anesthesia (induced by the following combination: TKX premedication (Tiletamin $2 \mathrm{mg} / \mathrm{kg}+$ zolazepam $2 \mathrm{mg} / \mathrm{kg}$ (Zoletil 100, Virbac) + ketamin $2 \mathrm{mg} / \mathrm{kg}$ (Narketan 10, Chassot) + Xylazin $0.4 \mathrm{mg} / \mathrm{kg}$ (Rometar $2 \%$, Spofa); $3 \mathrm{ml}$ IM Tracheal intubation + IV cannulation

\section{Surgery}

The acclimatization time of the minipig was 14 days. During the acclimatization and the study, a prophylactic antibiotic therapy was administered.

A general anesthesia was induced in the animal. The operating field was shaved and rinsed. The animal was transferred to the operating table and positioned into a prone position. The nine sites $(4 \times 4 \mathrm{~cm})$ designed for the corresponding samples was marked on the animal's back (Fig. 1a). There were seven nanofibrous dressings, one biological dressing (in the form of epidermis), and one control sample (Jelonet paraffin gauze).

The operating field was disinfected using Betadine and standardly draped.

Using a dermatome, the individual skin grafts were collected. One sample was placed into a specimen container with formaldehyde $(4 \%)$, to determine the thickness of the collected sample.

The wounds were dried using a sterile gauze and treated with saline containing epinephrine, to stop the bleeding (there was no excessive bleeding). Then, the wounds were covered using the nanofibrous dressings according to the provided scheme (Fig. 1b). Due to the handling difficulties, it was not possible to apply the PVA dressing $2 \mathrm{~g} / \mathrm{m}^{2}$. Therefore, the collected epidermis (biological cover) was re-administered instead of the PVA. 


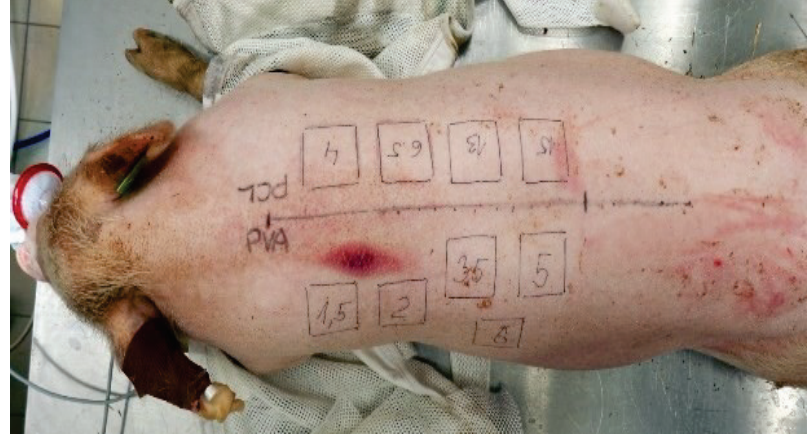

Fig. 1a. Animal model prior surgery. Sites intended to be covered with nanogauze with nanofibers prepared from different polymers (PCL and PVA) as well as with different mass density, respectively, are depicted.

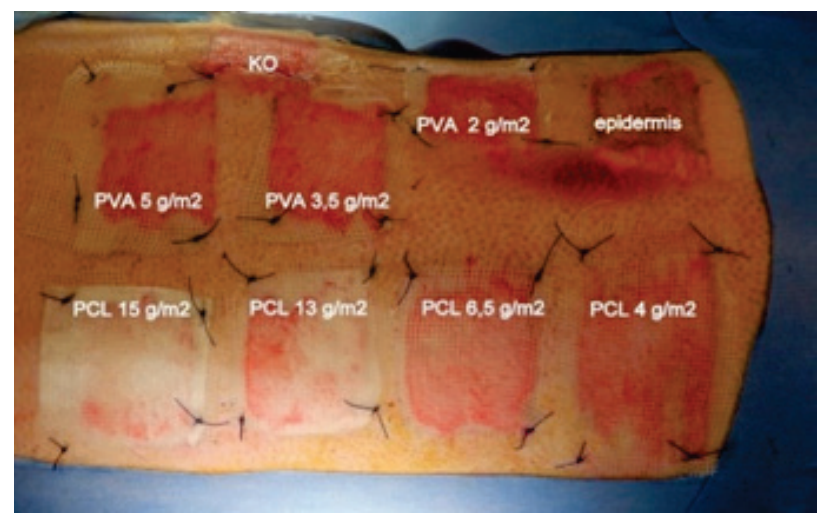

Fig. 1b. Animal model after surgery. Skin covers from $P C L$ and PVA scaffolds of different density (shown at $\mathrm{g} / \mathrm{m}^{2}$ ) and two control samples (KO stands for the first control - paraffin gauze dressing (Jelonet) and epidermis stands for the dressing using autologous epidermis), respectively.

A Jelonet paraffin gauze was used as a control dressing. The individual administered nanofibrous dressings were covered by Jelonet gauze; the corners of the gauze were fixed using stitches. Then, the operating field was covered by sterile gauze, fixed by Omnifix ${ }^{\circledR}$ adhesive, and a protective vest was used to prevent removal of the dressing.

\section{Histological examination}

The specimen containers with animal samples were labeled with name or code of the tested material, ID number of the animal and date of collection and transported to the histology laboratory. The punch biopsy samples (diameter $8 \mathrm{~mm}$ ) were collected from the interface between the healthy skin and the treated defect. Thus, they contained both intact and newly healing skin.

Formaldehyde was used to fix all the samples. The samples were trimmed and embedded in paraffin to allow them to be cut from the middle part where the newly healing skin was expected. The sections (thickness $5 \mu \mathrm{m})$ were stained using hematoxylin and eosin (HE), Weigert-van Gieson stain (WvG, visualization of collagen fibers), orcein (Or, to visualize elastin fibers), and Gomori's silver impregnation (Go, visualization of reticular fibers)

\section{Results}

\section{Wound appearance on day 5 after surgery}

Clinical manifestation was similar in all the tested samples. The wound margins were clear and dry. The defect margins showed signs of granulation. The skin graft was attached to the wound bed. There were no signs of inflammation (odor, secretion) (Fig. 2).

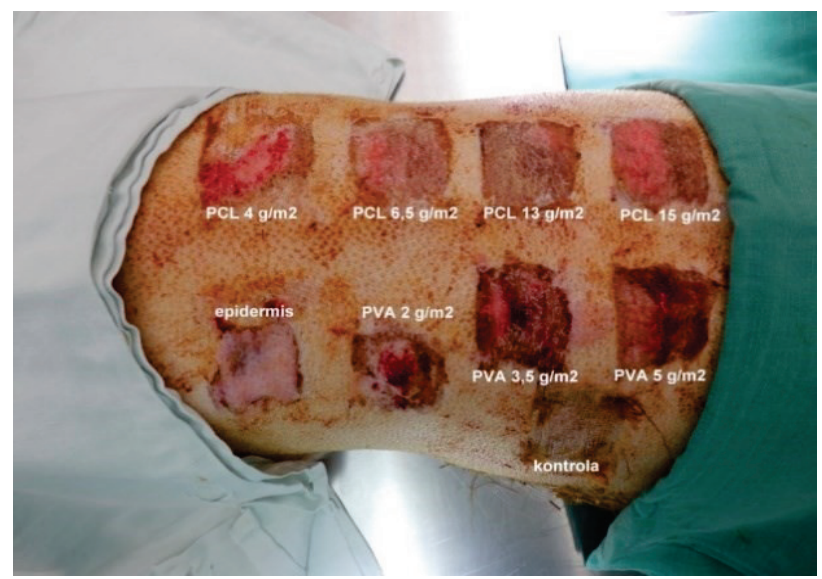

Fig. 2. Day 5 after surgery. Skin covers from $P C L$ and PVA scaffolds of different density (shown at $\mathrm{g} / \mathrm{m}^{2}$ ) and two control samples (KO stands for the first control - paraffin gauze dressing (Jelonet) and epidermis stands for the dressing using autologous epidermis), respectively.

\section{Histology}

In total, 12 skin samples collected on days 5, 12, and 27 after the procedure were evaluated.

Each skin set included four samples: (1) PCL nanofibrous dressing $13 \mathrm{~g} / \mathrm{m}^{2}$, (2) PVA nanofibrous dressing $3.5 \mathrm{~g} / \mathrm{m}^{2}$, (3) the first control - paraffin gauze dressing (Jelonet) and (4) the second control - dressing using autologous epidermis. In addition, one extra skin sample was collected during the procedure to evaluate the thickness and composition of the layer sliced off by the dermatome.

\section{Results on day 5 after surgery}

a) PCL nanofibrous dressing $13 \mathrm{~g} / \mathrm{m}^{2}$

The epidermis of the usual structure was 70-100 $\mu \mathrm{m}$ in thickness with rather reduced stratum 
granulosum (Fig. 3a). There were small crust residues on the surface. The dermal-epidermal junction revealed wavy appearance with distinct dermal papillae and epidermal ridges. The reticular lamina of epidermal basement membrane was well-developed and continuous. The papillary dermis was $50 \mu \mathrm{m}$ in thickness and composed of loose connective tissue containing relatively small number of cells, predominantly fibroblasts. Multiple thin collagen and reticular fibers together with scarce short elastic fibers were present in the entire layer. There was a prominent vascular plexus, especially at the interface of papillary and reticular layers (Fig. 3b). The reticular layer of dermis consisted of dense irregular connective tissue.

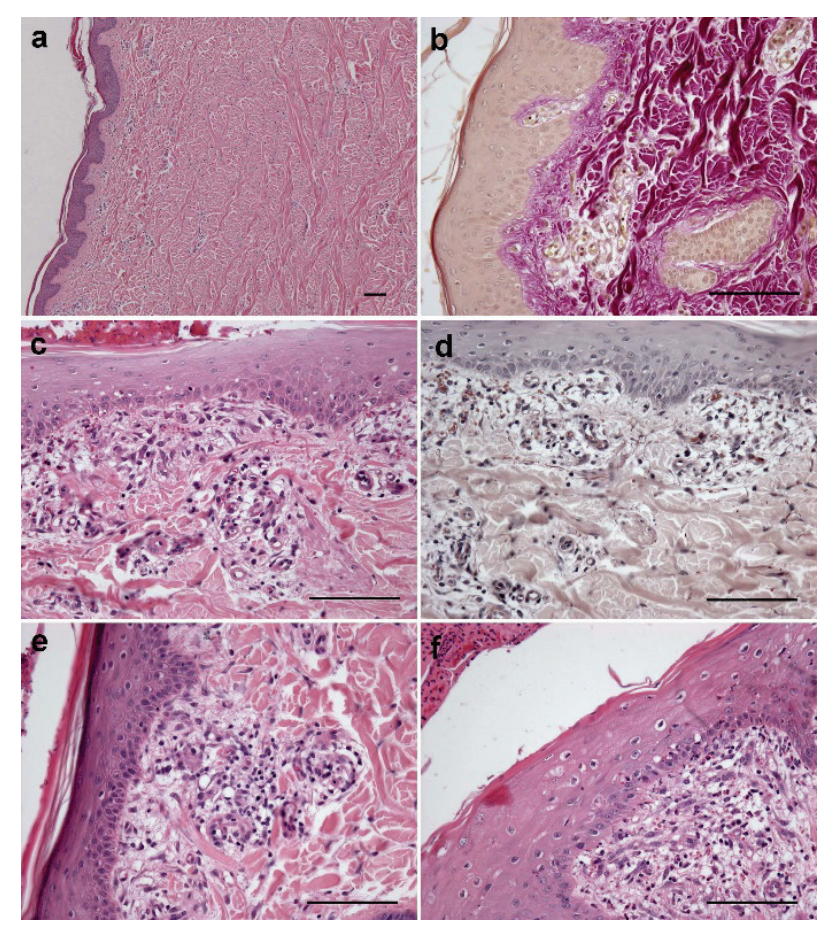

Fig. 3. Representative histological sections of the skin on the day 5 after surgery. a) $\mathrm{PCL}, \mathrm{HE}$, obj. 10x, b) $\mathrm{PCL}, \mathrm{WvG}$, obj. 40x, c) PVA, HE, obj. 40x, d) PVA, Or, obj. 40x, e) first control (Jelonet), $\mathrm{HE}$, obj. 40x, f) second control (autologous epidermis), $\mathrm{HE}$, obj. 40x. Bars $=100 \mu \mathrm{m}$.

\section{b) PVA nanofibrous dressing $3.5 \mathrm{~g} / \mathrm{m}^{2}$}

The epidermis was equal to the epidermis found in the PCL sample; crusts on the surface were thicker. The dermal-epidermal junction was flat, reticular lamina of basement membrane fragmented. The papillary dermis contained a large number of cells. Large activated fibroblasts prevailed, together with mast cells, less abundant lymphocytes, scare eosinophils (Fig. 3c). The extracellular matrix contained a very small number of collagen fibers, loose network of reticular fibers, and scarce elastic fibers (Fig. 3d). Prominent capillary networks were present.

\section{c) The first control - paraffin gauze dressing (Jelonet)}

The epidermis was thicker when compared to both previous specimens (up to $130 \mu \mathrm{m}$ ), its surface was free. The dermal-epidermal junction was wavy, reticular lamina of basement membrane continuous. The papillary dermis contained normal number of cells; fibroblasts prevailed, lymphocytes and scarce eosinophils were found near the capillaries (Fig. 3e). Number of reticular and elastic fibers was similar to the PCL sample.

\section{d) The second control - dressing using autologous epidermis}

The epidermis was intact with thick crust on the surface. The system of dermal papillae and epidermal ridges at the dermal-epidermal interface was fully developed; reticular lamina of basement membrane was fragmented. The papillary dermis was rich in cells, fibroblasts prevailed. In some part, multiple neutrophils and eosinophils were present under the epidermis (Fig. 3f). At these areas, only scarce thin collagen fibers were present; in other parts, their network was continuous. Elastic fibers were not present in the papillary dermis, reticular fibers were scarce.

\section{Results on day 12 after surgery}

Clinical manifestation was similar in all the tested samples: The wound margins were clear and dry. The defect margins showed signs of granulation. The dressings were partly stripped during bandage change. There were no signs of inflammation (odor, secretion) (Fig. 4).

\section{Histology after 12 days}

\section{a) PCL nanofibrous dressing $13 \mathrm{~g} / \mathrm{m}^{2}$}

The epidermis was $100-130 \mu \mathrm{m}$ thick, of normal structure with well-developed all layers including stratum granulosum. The system of papillae and epidermal ridges at the dermal-epidermal interface was fully developed (Fig. 5a), reticular lamina of basement membrane was fragmented (Fig. 5b). The papillary dermis revealed usual structure, fibroblasts prevailed, other cells were scarce (eosinophils, mast cells, lymphocytes). A dense network of thin collagen fibers prevailed in the connective tissue, reticular fibers were less numerous, there were almost no elastic fibers. The number of blood vessels diminished in comparison to the sample collected after 5 days. 


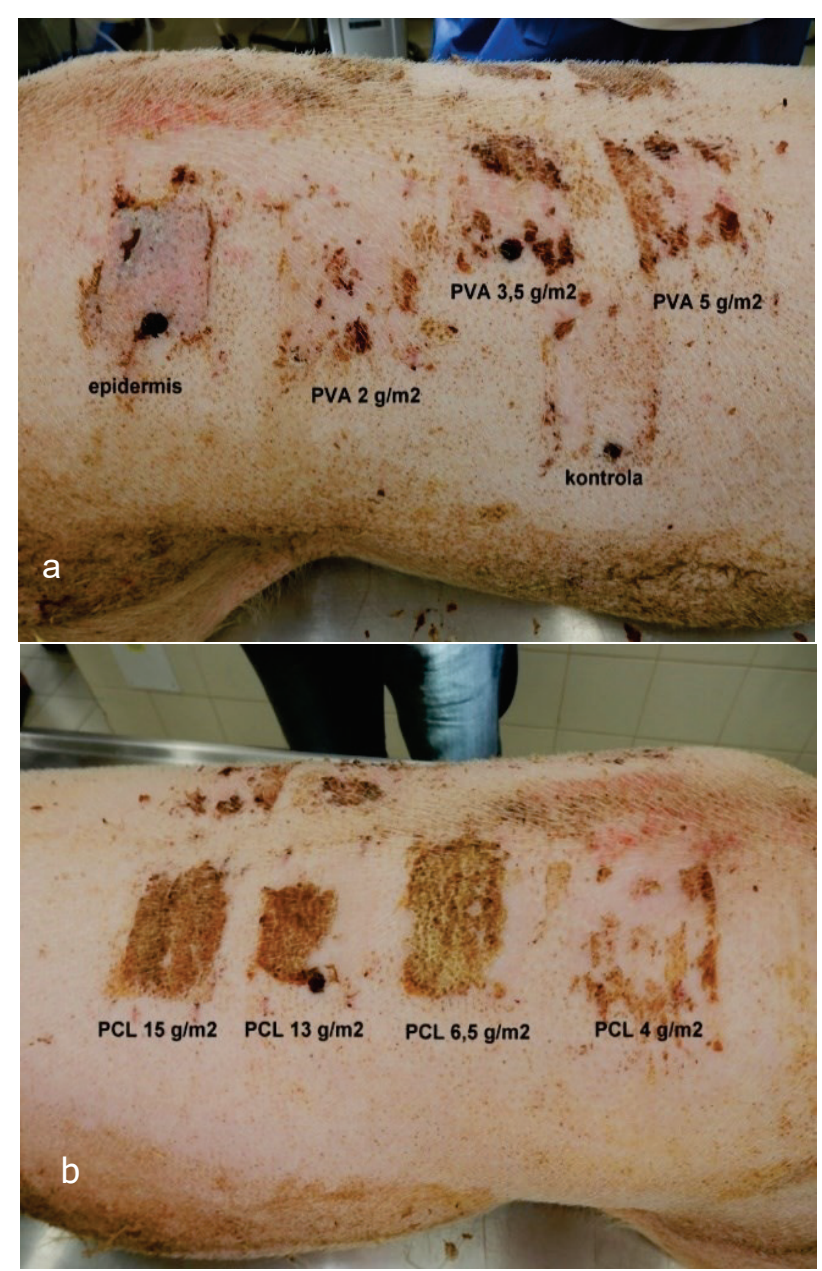

Fig. 4. Day 12 after surgery. Skin covers from $P C L$ and $P V A$ scaffolds of different density (shown at $\mathrm{g} / \mathrm{m}^{2}$ ) and two control samples (kontrola stands for the first control - paraffin gauze dressing (Jelonet) and epidermis stands for the dressing using autologous epidermis), respectively. a) PVA, b) PCL

\section{a) PVA nanofibrous dressing $3.5 \mathrm{~g} / \mathrm{m}^{2}$}

The thickness of the epidermis was 70-90 $\mu \mathrm{m}$; its structure was normal however, the dermal-epidermal junction was still flattened (Fig. 5c). The reticular lamina of basement membrane was significantly reduced. The papillary dermis contained highly vascularized areas with increased number of lymphocytes, macrophages, and eosinophilic granulocytes, resembling inflammatory infiltrates (Fig. 5d). Outside of the infiltrates, a dense network of thin collagen fibers was present; less numerous reticular fibers and no elastic fibers were detected.

\section{b) The first control - paraffin gauze dressing (Jelonet)}

The epidermis 70-90 $\mu \mathrm{m}$ in thickness with normal structure and crust residues on the surface. The dermalepidermal junction was fully developed with continuous reticular lamina of basement membrane. The papillary dermis contained normal number of cells and vessels (Fig. 5e). There was a dense network of thin collagen fibers, loose network of fine reticular fibers, and no elastic fibers.

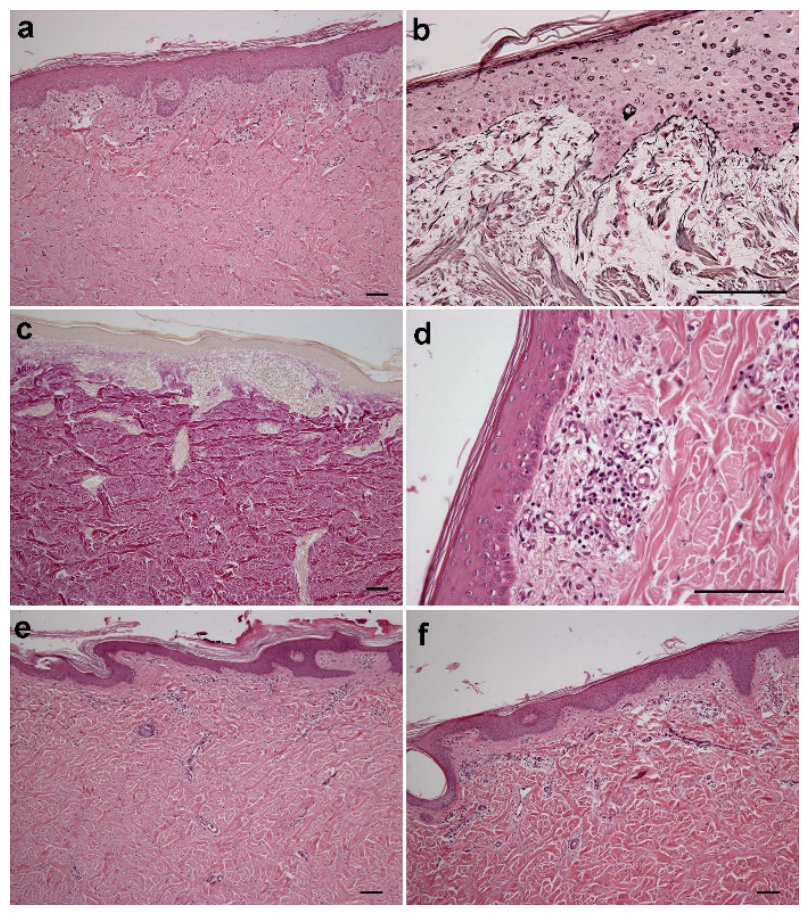

Fig. 5. Representative histological sections of the skin on the day 12 after surgery. a) $\mathrm{PCL}, \mathrm{HE}$, obj. 10x, b) $\mathrm{PCL}, \mathrm{Go}$, obj. 40x, c) PVA, WvG, obj. 10x, d) PVA, HE, obj. 40x, e) first control (Jelonet), $\mathrm{HE}$, obj. 10x, f) second control (autologous epidermis), $\mathrm{HE}$, obj. 10x. Bars $=100 \mu \mathrm{m}$.

c) The second control - dressing using autologous epidermis

The epidermis measured $70-100 \mu \mathrm{m}$, its structure was normal. There was the fully developed dermalepidermal junction and continuous reticular lamina. The papillary dermis contained normal number of cells and multiple collagen, reticular, and elastic fibers (Fig. 5f).

\section{Wound appearance on day 27 after surgery}

Clinical manifestation was similar in all the tested samples. The wound margins were clear and dry. The defects were filled with granulation tissue. There were no signs of inflammation (odor, secretion) (Fig. 6).

The animal survived until the day of the planned euthanasia. During the study, the health condition of the animal was good. The course of the post-operative period was good, there were no secondary complications, and it did not affect the animal's daily activities (physical activity, water and food intake, excretion). 
No therapy-associated clinical changes were observed. The body weight of the animal gradually increased during the experiment; the increase corresponded with the age of the animal. No adverse effect on of the tested nanogauze materials (PVA, PCL) on its body weight was detected.

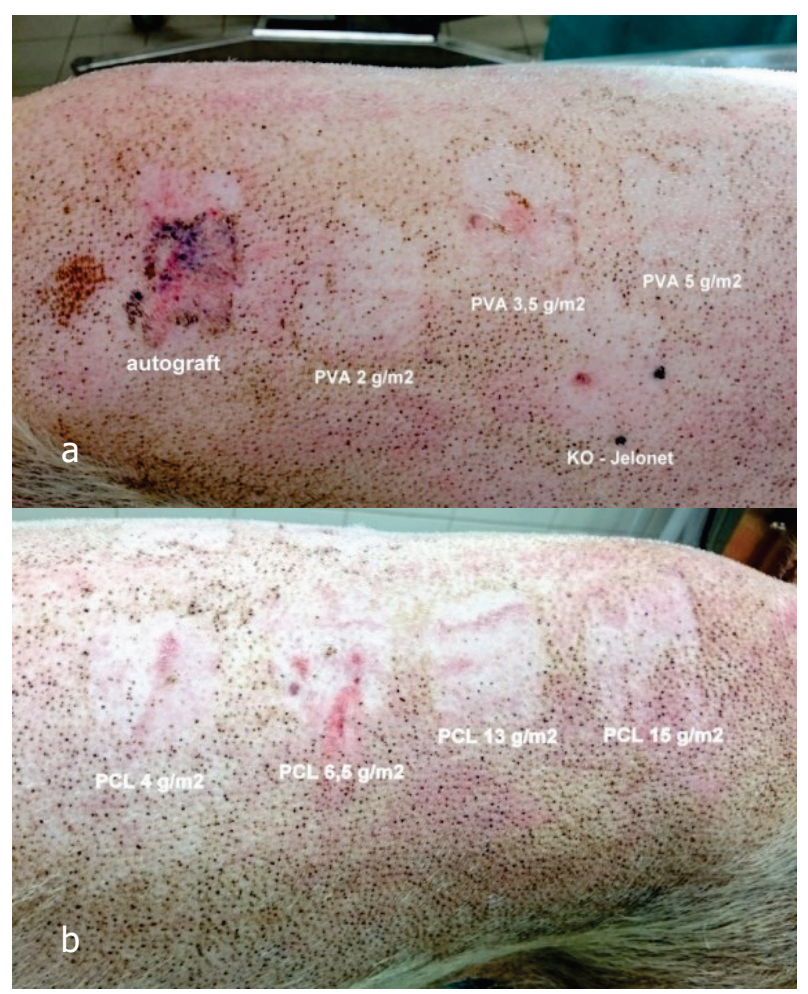

Fig. 6. Day 27 after surgery. Skin covers from PCL and PVA scaffolds of different density (shown at $\mathrm{g} / \mathrm{m}^{2}$ ) and two control samples (KO stands for the first control - paraffin gauze dressing (Jelonet) and epidermis stands for the dressing using autologous epidermis), respectively. Skin covers from PCL and PVA scaffolds of different density (shown at $\mathrm{g} / \mathrm{m}^{2}$ ) and two control samples (KO stands for the first control - paraffin gauze dressing (Jelonet) and epidermis stands for the dressing using autologous epidermis), respectively. a) PVA b) PCL

\section{Histology after 27 days}

\section{a) PCL nanofibrous dressing $13 \mathrm{~g} / \mathrm{m}^{2}$}

The epidermis was $100-130 \mu \mathrm{m}$ thick, with normal structure. The dermal-epidermal junction was flattened with fragmented reticular lamina; the papillary dermis contained normal number of cells, multiple collagen fibers, some reticular fibers and no elastic fibers (Fig. 7a).

\section{b) PVA nanofibrous dressing $3.5 \mathrm{~g} / \mathrm{m}^{2}$}

The epidermis was approximately $100 \mu \mathrm{m}$ thick, with normal structure. The dermal-epidermal junction was flattened; the reticular lamina was continuous. The papillary dermis still contained cellular infiltrates with majority of macrophages and some giant cells (usually seen in the vicinity of a foreign body) (Fig. 7b). There were no elastic fibers.

\section{c) The first control - paraffin gauze dressing (Jelonet).}

The epidermis measured approximately $100 \mu \mathrm{m}$ in thickness; its structure was normal. The dermalepidermal junction was rich in papillae and its reticular lamina was continuous; the papillary dermis contained multiple collagen and elastic fibers (Fig. 7c).

\section{d) The second control - dressing using autologous epidermis.}

The epidermis was approximately $100 \mu \mathrm{m}$ thick, with normal structure. The dermal-epidermal junction formed many papillae; there was a continuous reticular lamina. The papillary dermis contained multiple collagen and elastic fibers (Fig. 7d).

Thickness of the graft sample collected during the procedure was $660 \mu \mathrm{m}$. The sample was composed of the epidermis (approximately $100 \mu \mathrm{m}$ ), the papillary dermis (approximately $100 \mu \mathrm{m}$ ), and a portion of the reticular dermis containing a dense network of collagen fibers.

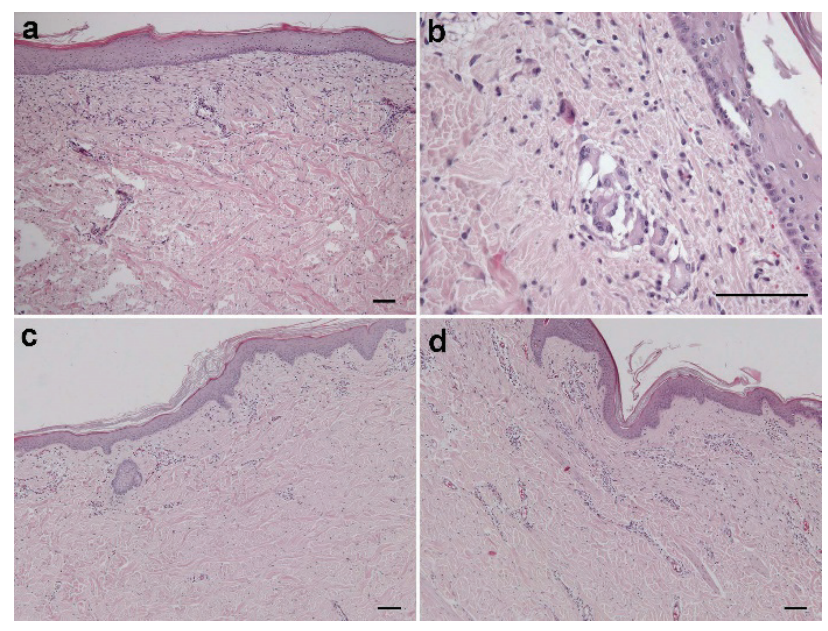

Fig. 7. Representative histological sections of the skin on the day 27 after surgery. a) PCL, HE, obj. 10x, b) PVA, HE, obj. 40x, c) first control (Jelonet), $\mathrm{HE}$, obj. 10x, d) second control (autologous epidermis), HE, obj. 10x. Bars $=100 \mu \mathrm{m}$.

\section{Discussion and Conclusions}

All animal survived until the end of the experiment. The healing process was evaluated as positive, there were no complications during the surgery nor the recovery.

The laboratory minipig tolerated the procedure well. Furthermore, the minipig tolerated the therapy with PVA nanogauze and PCL nanogauze therapy as well, no 
complications were observed during the healing period. The healing of the defects was partially influenced by the biology of the tested animal. The dressings were relatively well tolerated but the animal considered bandage as a foreign object and tried to remove it. Therefore, the dressings shifted and the superficial layer in the healing defect was removed. No signs of infection were observed in any of the defects.

There were no inflammatory infiltrates or foreign body reactions in the wounds treated with PCL dressings. Mild inflammatory infiltrates were observed in the defects treated with PVA dressings. These infiltrates were likely caused by the presence of material debris, as PVA is the only water-soluble material. Macroscopically, the defects treated with PVA dressings showed superior properties when compared to the PCL-treated defects.

Macroscopic evaluation of the treated and control defects did not show any negative effects of the used dressings (PVA nanogauze and PCL nanogauze) on the surrounding tissue. The defects treated with the tested materials healed in a similar manner to the control defect. The defects were almost completely healed 12 days after the surgery. The newly formed tissue was functional, there were no signs of scarring. The defects treated with the PVA appeared to be healed in a superior manner; the surface of the newly formed skin was smoother. In all the tested defects, the crusts were removed easily.

Microscopically, there was no difference in healing of the defect treated with autologous epidermis and control paraffin gauze. In both cases, healing with restitutio ad integrum occurred. The defect covered with PCL was healed, however, deviations from normal healing were observed, including flattened dermoepidermal junction and missing elastin fibers in papillary dermis. The healing of the PVA-covered defect was associated with inflammatory infiltrates containing macrophages and giant cells. The dermoepidermal junction was also flattened and there were no elastic fibers. The inflammatory infiltrates may have been caused by a reaction to tiny debris of the degrading material, as PVA is the tested material soluble in water.

We can conclude that the nanofiber scaffold which was well tolerated, could be used as a smart skin cover which could be functionalized with another bioactive substances directly on the surgeon table, among potential bioactive substances belong platelet derivatives, antibiotics, etc. The main advantage of this approach is a full biodegradation of skin cover which leads to scar minimizing.

\section{Conflict of Interest}

There is no conflict of interest.

\section{Acknowledgements}

Study was supported by the Internal Grant Agency of the Ministry of Health of the Czech Republic 16-28637A (Bones, tendons and ligaments extent defects healing with using of new biomaterials).

\section{References}

CROVETTI G, MARTINELli G, ISSI M, BARONE M, GUIZZARDI M, CAMPANATI B, MORONI M, CARABELLI A: Platelet gel for healing cutaneous chronic wounds. Transfus Apher Sci 30: 145-151, 2004.

BARRIENTOS S, STOJADINOVIC O, GOLINKO MS, BREM H, TOMIC-CANIC M: Growth factors and cytokines in wound healing. Wound Repair Regen 16: 585-601, 2008.

WERNER S, GROSE R: Regulation of wound healing by growth factors and cytokines. Physiol Rev 83: 835-870, 2003.

RIEGER KA, BIRCH NP, SCHIFFMAN JD: Designing electrospun nanofiber mats to promote wound healing a review. J Mater Chem 36: 4531-4541, 2013.

MUSTOE T: Understanding chronic wounds: a unifying hypothesis on their pathogenesis and implications for therapy. Am J Surg 187: 65S-70S, 2004.

HESS CT: The art of skin and wound care documentation. Home Healthcare Nurse 23: 502-513. 2005.

ZAHEDI P, REZAEIAN I, RANAEI-SIADAT SO, JAFARI SH, SUPAPHOL P: A review on wound dressings with an emphasis on electrospun nanofibrous polymeric bandages. Polym Adv Technol 21: 77-95, 2010.

CHAKRABORTY PD, DE D, BANDYOPADHYAY S: Human aqueous placental extract as a wound healer. $J$ Wound Care 18: 464-467, 2009.

CHEW SY, WEN Y, DZENIS Y, LEONG KW: The role of electrospinning in the emerging field of nanomedicine. Curr Pharm Des 12: 4751-4770, 2006. 
CHEN FM, ZHANG M, WU ZF: Toward delivery of multiple growth factors in tissue engineering. Biomaterials 31: 6279-6308, 2010. 